\title{
ANALISIS BEBAN PENDINGIN PADA RUANG KULIAH PRODI NAUTIKA JURUSAN KEMARITIMAN
}

\author{
Mika Patayang ${ }^{(1)}$, Erry Yadie ${ }^{(2)}$ \\ Staf Pengajar Jurusan Kemitraan Polnes Samarinda ${ }^{1,2}$ ) \\ jl. batu cermin sempaja ujung kampus kemaritiman polnes samarinda \\ patayangmika nautikapolnes@yahoo.com
}

\begin{abstract}
ABSTRAK
Kenyamanan dalam suatu ruangan merupakan hal yang sangat penting dalam menunjang efektifitas kegiatan seseorang berada dalam ruang yang sejuk membuat semua orang merasa nyaman oleh karenan itu pengkondisian udara suatu ruangan sangat perlu diperhatikan.

Pada penelitian ini dilakukan untuk menghitung beban pendingin pada ruang kuliah nautika pada Jurusan Kemaritiman dimana dalam penelitian ini beban pendingin berasal dari perpindahan panas melalui dinding, perpindahan panas melalui kaca, panas dari taruna/I dan panas dari lampu.

Penelitian dilakukan pada pukul 08.00;12.00 dan 16.00 dari hasil penelitian diperoleh bahwa beban pendingin pada pukul 08.00 sebesar 6384,990 Watt, beban pendingin pada pukul 12.00 sebesar 3719,3402 Watt, bebab pendingin pada pukul 16.00 sebesar 4886,9729 Watt. dari hasil diatas disarankan bahwa untuk memperoleh kenyamanan dalam ruang kelas nautika dibutuhkan minimal 2 AC 1 PK
\end{abstract}

Kata kunci : refigerasi, beban pendigin

\section{PENDAHULUAN}

Sistem pengkondisian udara dewasa ini memang berperan penting. Hal ini terlihat semakin banyak digunakan perlengkapan ini secara luas diberbagai bidang kegiatan manusia antara lain ruang kerja, gudang pendinginan bahkan pengkondisian udara di kendaraan semuanya itu bertujuan agar setiap orang yang berada dalam ruanga tersebut merasa nyaman. Pengkondisian udara merupakan suatu kemewahan, namun telah menjadi kebutuhan yang harus dipenuhi, tanpa adanya peralatan ini banyak kegiatan yang tidak dapat dilakukan dengan baik, apa lagi kegiatan yang dilakukan didalam ruangan seperti prosen belajar mengajar demi untuk menunjang berjalannya proses belajar mengajar dengan baik maka ruangan perkuliahan khususnya di prodi Nautika Jurusan Kemaritiman (gambar 1. ruang perkuliahan tampak samping).

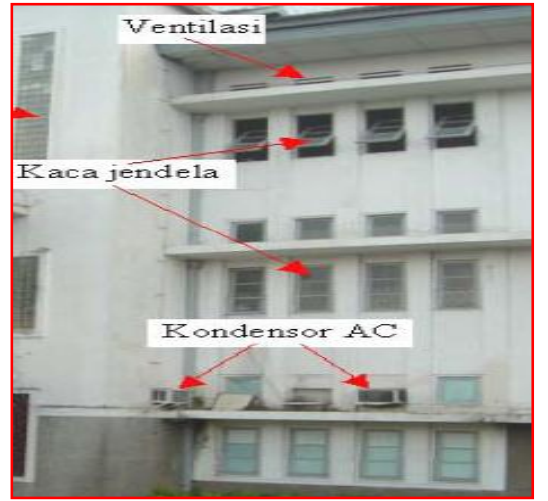

Gambar 1. Ruang perkuliahan tampak samping

Di hitung beban pendinginannya agar pengkondisian udara dalam ruangan tersebut dapat dilakukan dengan baik agar dapat memberikan kenyamanan bagi taruna/I dan dosen pada saat proses belajar mengajar. Mengingat kegiatan taruna/I pada prodi Nautika Jurusan kemaritiman sangat padat dimana sebelum memulai perkuliahan para taruna/iwajib mengikuti apel pagi kurang lebih 30 menit dan setelah itu taruna/I berlari menggelilingi kampus dan juga melakukan kegiatan lainnya maka secara otomatis mereka mengeluarkan keringat akibat adanya kegiatan tersebut dan setelah itu 
mereka harus masuk ruangan kelas untuk melakukan proses belajar mengajar dan jika ruangan kelas tersebut udaranya tidak dikondisikan maka kenyamanan dalam kelas tidak ada atau jika pengkondisian udaranya tidak tidak sesuai dengan jumlah beban pendinginannya maka kenyamanan dalam ruangan perkuliahan itu tidak dapat tercapai maka sangat penting untuk menganalisa beban pending pada ruangan kelas agar dapat memperlancar prosen belajar mengajan oleh karena penelitian " akan dilakukan. Analisa Beban Pendingin Pada Ruang Kuliah Prodi Nautika Jurusan Kemaritiman"

\section{LANDASAN TEORI}

Udara panas menyebabkan rasa tidak nyaman untuk beraktifitas.Kondisi akan semakin parah apabila orang bekerja atau beraktifitas di dalam ruang yang tertutup dengan sirkulasi udara yang terbatas. Udara dengan kelembaban tinggi dapat menimbulkan rasa tidak nyaman, hal ini karena pada kondisi tersebut orang menjadi mudah berkeringat. Untuk mengatasi kondisi tersebut, udara di dalam ruangan harus dikondisikan sehingga mempunyai karakteristik yang cocok dengan kondisi tubuh orang yang menempati ruangan. Di dalam suatu ruangan yang udaranya dikondisikan, temperatur dan kelembaban udara dapat dikontrol sampai kondisi dimana penghuni ruangan merasa nyaman. Peralatan yang dapat dipakai untuk pengkondisian udara biasanya adalah air conditioner (AC), humidifier (pelembab), fan atau blower. Disamping untuk mengontrol temperatur udara, AC dapat digunakan sekaligus untuk sirkulasi sehingga kondisi udara tetap bersih. Fan dan bower hanya digunakan untuk sirkulasi udara saja.gambar komponen mesin pendingin dan diagram P-h dapat dilihat pada gambar 2.

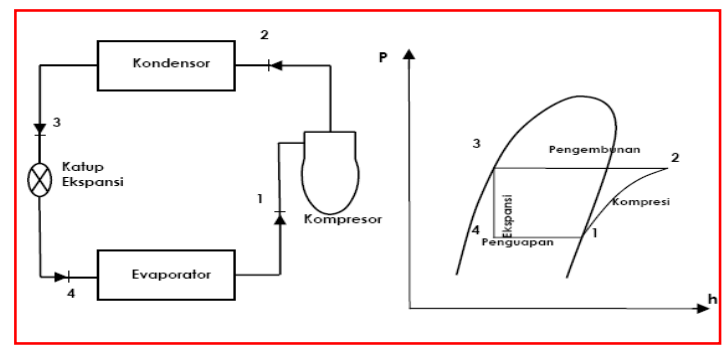

Gambar 2. komponen utama mesin pendingin dan diagram $P-h$
Air conditioner atau alat pengkondisi udara termasuk jenis mesin yang bekerja mengikuti siklus termodinamika yaitu siklus kompresi uap atau daur kompresi uap. Fluida kerja yang dipakai untuk daur ini biasa dinamakan refrigeran. Daur kompresi uap diaplikasikan pada mesin-mesin refrigerasi.Sebagai contoh adalah freezer, mesin ini banyak dipakai untuk mengkondiskan benda pada suhu rendah. Sebagai contoh bahan pangan seperti buahbuahan, sayur-mayur, makanan kaleng, atau lainnya sering ditempatkan di dalam freezer supaya lebih awet dan tetap segar. Freezer banyak dipakai industri makanan atau industri obat untuk pegawetan..

Teknik pengkondisian udara adalah teknik memidahkan panas dari atau ke suatu rungan sehingga diperoleh temperatur dan kelembaban udara yang diinginkan. Mesin yang dapat melakukan perpindahan itu adalah heat pump. Ada dua macam pompa kalor bergantung dari kebutuhan akan panas atau tidak membutuhkan panas. Mesin pompa panas yang menyerap panas dari suhu ruangan kemudian dibuang kelingkungan disebut mesin pendingin. Sedangkan mesin pompa kalor yang menyerap panas dari lingkungan untuk dipakai untuk memanasii ruangan disebut pompa kalor

Tujuan dari memindahkan panas dari satu tempat ke tempat lainnya adalah untuk mengkondisikan udara dengan temperatur dan kelembaban yang pas untuk kenyamanan, atau untuk lainnya seperti pengawetan, dan pengeringan.

Sebagai contoh ruangan kelas untuk proses belajar mengajar, pada musim panas atau kemarau, ruangan cenderung panas pada waktu proses pengajaran. Beban pendinginan diperoleh dari suhu lingkungan, radiasi matahari, para siswa dan guru. Beban pendinginan paling besar diperoleh dari pemanasan radiasi matahari. Dengan menganalisis bebanbeban pendinginan, dapat dibuat rancangan sistem untuk mengkondisikan udara di dalam ruangan kelas menjadi nyaman untuk proses pengajaran.

Seandainya indikasi kenyamanan kelas hanya terpaku pada temperatur saja, misalkan temperatur ruang kelas pada 25 0C yaitu sama dengan temperatur di luar kelas, proses pengkondisian udara harus dapat mencapai 
temperatur tersebut. Sebagai contoh penyelesaiannya adalah dengan memasang kipas sedemikian hingga sirkulasi udara lancar, ditambah dengan pemasangan tabir matahari pada jendela kaca untuk megurangi efek radiasi panas matahari.

Kalau kebutuhan kenyamanan dirasa pada temperatur yang lebih rendah lagi, misalkan pada $180 \mathrm{C}$, sehingga harus dipasang air conditioner (AC) yang mampu mengkondisikan udara sampai temperatur tersebut. Jendela-jendela kaca harus dengan tabir matahari ditutup untuk menghindari beban pendinginan yang besar dari radiasi matahari. AC akan bekerja menyerap kalor dari ruangan kelas kemudian dibuang kelingkungan di luar kelas. Karena ruang kalas, sebagian kalor nya diserap AC, temperaturnya menjadi turun. Biasanya berbarengan dengan proses penyerapan kalor kelembaban udara juga ikut berubah karena temperatur turun, ada sebagian uap air di dalam kelas mengembun, sehingga kadar uap air di dalam ruangan kelas menurun. Dari contoh tersebut terlihat bahwa proses pengkondisian udara bukan berarti hanya proses pendinginan, tetapi proses untuk pencapaian temperatur yang dirasa nyaman bagi pengguna ruangan.

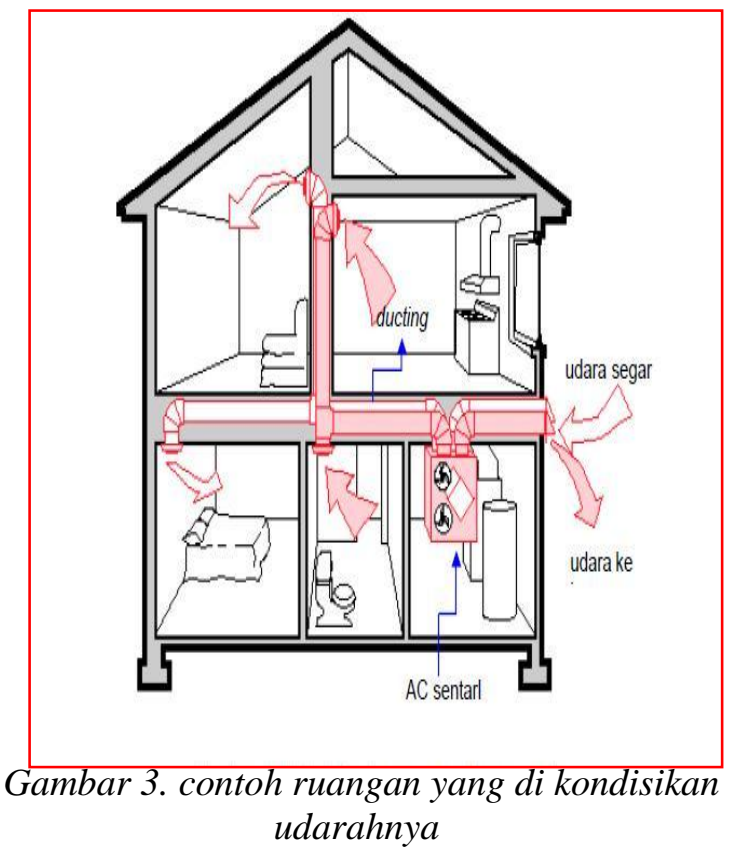

\section{METODE PENELITIAN}

\section{Waktu dan Tempat Penelitian}

a. Waktu Penelitian.

Penelitian ini akan di laksanakan pada tanggal 20 mei- 30 mei 2014.

b. Tempat Penelitian

Ruang perkuliahan Prodi Nautika Jurusan Kemaritiman.

\section{Metode Pengumpulan Data}

a. Observasi dimana melakukan pengamatan, pengukuran dan pencatatan dilapangan yang nantinya menjadi data primer.

b. Metode kepustakaan

\section{Jenis Data}

a. Data primer berupa temperature ruangan program studi nautika dan dimensi dari ruangan tersebut.

b. Data sekunder berupa data dari spesifikasi dari air condisening (AC)

\section{HASIL PENELITIAN}

\section{A.Hasil Penelitian}

Data yang diperoleh

\begin{tabular}{|c|l|c|}
\hline No. & \multicolumn{1}{|c|}{ Item } & Jumlah \\
\hline 1. & Lampu & 8 \\
\hline 2. & Kaca & 8 \\
\hline 3. & Orang & 24 \\
\hline 4. & Pintu & 1 \\
\hline
\end{tabular}

Keterangan

1. Ukuran gedung $=350 \mathrm{~cm} \mathrm{x} 900 \mathrm{~cm} \mathrm{\&}$ $500 \mathrm{~cm}$ x $350 \mathrm{~cm}$

2. Tebal dinding $=3,5 \mathrm{~m}=350 \mathrm{~cm}$

3. Ukuran kaca $=40 \mathrm{~cm} \times 100 \mathrm{~cm}$ (jenis kaca tunggal (4 mm))

4. Pintu $=160 \mathrm{~cm} \times 200 \mathrm{~cm}$

5. Kondisi cuaca $=$ Cerah 


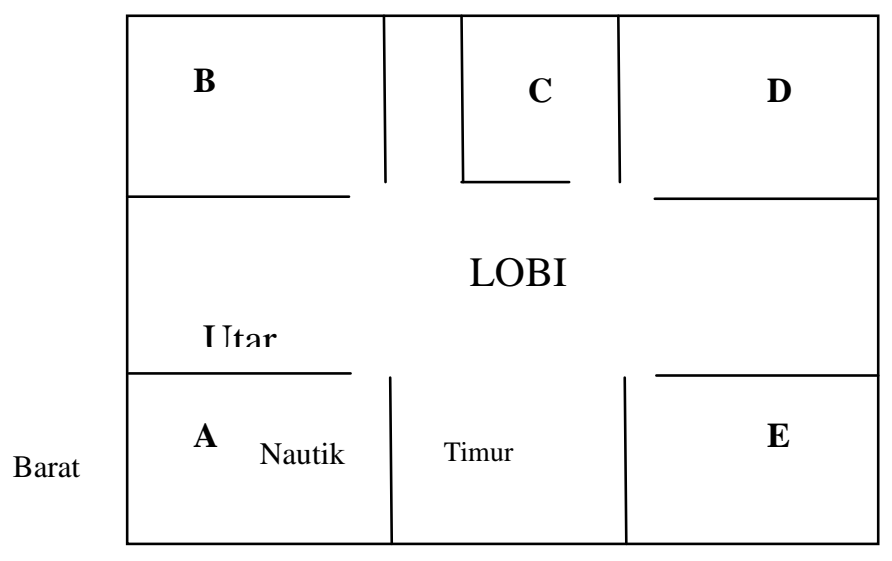

Selata

Gambar 4. Gedung

Perhitungan untuk pukul 08.00;12:00;16.00

1. Luas Gedung

Luas $1=350 \mathrm{~cm} \times 900 \mathrm{~cm}=315.000$ $\mathrm{cm}^{2}$ ( sisi selatan)

Luas $2=500 \mathrm{~cm} \times 350 \mathrm{~cm}=175.000$ $\mathrm{cm}^{2}$ (sisi barat)

2. Luas Kaca $=40 \mathrm{~cm} \times 100 \mathrm{~cm} \times 8=$ $32.000 \mathrm{~cm}^{2}$

3. Luas Pintu $=160 \mathrm{~cm} \times 200 \mathrm{~cm}=32.000$ $\mathrm{cm}^{2}$

4. Perolehan kalor melalui dinding $\mathrm{qw}=[\mathrm{UA}(\mathrm{CLTD})$ barat $]+[\mathrm{UA}(\mathrm{CLTD})$ selatan] dimana $\mathrm{U}=2,6315 \mathrm{w} / \mathrm{m}^{2} \mathrm{k}$

Tabel 1. untuk CLTD

\begin{tabular}{|c|c|c|c|}
\hline \multirow{2}{*}{ Arah Jam } & 08.00 & 12.00 & 16.00 \\
\hline Selatan & 2 & 6 & 12 \\
\hline Barat & 2 & 6 & 22 \\
\hline
\end{tabular}

Untuk jam 08.00

$$
\begin{aligned}
\text { Qw } \quad & =\left[2,6315 \mathrm{w} / \mathrm{m}^{2} \mathrm{k} \times 17,5 \mathrm{~m}^{2} \mathrm{x}\right. \\
& 2]+\left[2,6315 \mathrm{w} / \mathrm{m}^{2} \mathrm{k} \times 28,8 \mathrm{~m}^{2} \mathrm{x}\right. \\
& 2] \\
= & 92,1025+113,2 \\
= & 205,3025
\end{aligned}
$$

Untuk jam 12.00

Qw $=\left[2,6315 \mathrm{w} / \mathrm{m}^{2} \mathrm{k} \times 17,5 \mathrm{~m}^{2} \times 6\right]+$ $\left[2,6315 \mathrm{w} / \mathrm{m}^{2} \mathrm{k} \times 28,3 \mathrm{~m}^{2} \times 6\right]$ $=276,3075+446,8287$ $=723,1362$

Untuk jam 16.00

$\mathrm{Qw}=\left[2,6315 \mathrm{w} / \mathrm{m}^{2} \mathrm{k} \times 17,5 \mathrm{~m}^{2} \times 22\right]$

$+\left[2,6315 \mathrm{w} / \mathrm{m}^{2} \mathrm{k} \times 28,8 \mathrm{~m}^{2} \times 12\right]$

$=1013,1275+893,6574$

$=1906,7849$

Tabel 2. peroleh kalor melalui dinding

\begin{tabular}{|c|c|c|c|}
\hline \multirow{2}{*}{$\begin{array}{c}\text { Wakt } \\
\mathrm{u}\end{array}$} & \multicolumn{2}{|c|}{ Perolehan Panas } & \multirow{2}{*}{ Total } \\
\cline { 2 - 3 } & Barat & Selatan & \\
\hline 08.00 & 92,1025 & 113,2 & 205,3025 \\
\hline 12.00 & 276,3075 & $\begin{array}{c}446,828 \\
7\end{array}$ & 723,1362 \\
\hline 16.00 & 1013,127 & 893,657 & 1906,784 \\
& 5 & 4 & 9 \\
\hline
\end{tabular}

\section{Perolehan kalor melalui kaca}

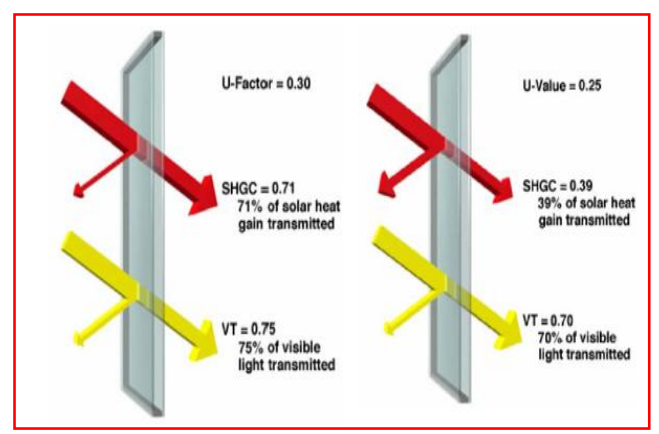

Gambar 5. radiasi matahari melalui kaca

Qsq $=\left[\right.$ A.I $\mathrm{I}_{\mathrm{T}}$. (shading) $]$ selatan

Dimana :

$\mathrm{A}=$ luas total jendela

$\mathrm{I}_{\mathrm{T}}=$ radiasi matahari

$\mathrm{Z}=$ factor transmisi

Shading $=$ factor bayangan

Tabel 3. Untuk radiasi matahari

\begin{tabular}{|c|c|}
\hline Azimut & Radiasi \\
\cline { 2 - 2 } Waktu & Selatan \\
\hline 08.00 & 54 \\
\hline 12.00 & 67 \\
\hline 16.00 & 54 \\
\hline
\end{tabular}


Kaca biasa $\zeta=0,70$

Shading $=0,55$ (terang)

Untuk jam 08.00

$$
\begin{aligned}
\text { Qsg } & =\left[3,2 \mathrm{~m}^{2} \times 54 \times 0,7 \times 0,55\right] \\
& =66,528
\end{aligned}
$$

Untuk jam 12.00

$$
\begin{aligned}
\text { Qsg } & =\left[3,2 \mathrm{~m}^{2} \times 67 \times 0,7 \times 0,55\right] \\
& =82,544
\end{aligned}
$$

Untuk jam 16.00

$$
\begin{aligned}
\text { Qsg } & =\left[3,2 \mathrm{~m}^{2} \times 54 \times 0,7 \times 0,55\right] \\
& =66,528
\end{aligned}
$$

Tabel 4. Perolehan kalor dari kaca

\begin{tabular}{|c|c|c|}
\hline \multirow{2}{*}{ Waktu } & $\begin{array}{c}\text { Perolehan } \\
\text { panas }\end{array}$ & \multirow{2}{*}{ Total } \\
\cline { 2 - 2 } & Selatan & \\
\hline 08.00 & 66,528 & 66,528 \\
\hline 12.00 & 82,544 & 82,544 \\
\hline 16.00 & 66,528 & 66,528 \\
\hline
\end{tabular}

5. Perolehan panas melalui Manusia Jumlah penghuni/taruna $=30$ orang Jenis pekerjaan

\begin{tabular}{|l|l|l|}
\hline 08.00 & $=300 \mathrm{w}$ & 35 \\
\hline 12.00 & $=150 \mathrm{w}$ & 25 \\
\hline 16.00 & $=150 \mathrm{w}$ & 25 \\
\hline
\end{tabular}

Untuk jam 08.00

$$
\begin{aligned}
\text { Kalor Sensibel } & =0,35 \times 300 \times 0,58 \times 30 \\
& =1827 \mathrm{w} \\
\text { Kalor Laten } & =0,45 \times 300 \times 30 \times 1 \\
= & 4050 \mathrm{w}
\end{aligned}
$$

Untuk jam 12.00

Kalor Sensibel $=0,75 \times 150 \times 0,58 \times 30$

$$
=625,5 \mathrm{w}
$$

Kalor Laten $\quad=0,45 \times 150 \times 30 \times 1$

$$
=2025 \mathrm{~W}
$$

Untuk jam 16.00

Kalor Sensibel $=0,25 \times 150 \times 0,58 \times$

30

$$
=652,5 \mathrm{w}
$$

Kalor Laten $\quad=0,45 \times 150 \times 30 \times 1$

$$
=2025 \mathrm{w}
$$

Tabel 5. Perolehan kalor laten

\begin{tabular}{|c|c|c|c|}
\hline \multirow{2}{*}{ Waktu } & \multicolumn{2}{|c|}{ Kalor } & \multirow{2}{*}{ Total } \\
\cline { 2 - 3 } & Laten & Sensibel & \\
\hline 08.00 & 4050 & 1827 & 5877 \\
\hline 12.00 & 2025 & 652,5 & 2677,5 \\
\hline 16.00 & 2025 & 652,5 & 2677,5 \\
\hline
\end{tabular}

Beban kalor lampu

Asumsi jumlah lampu $=8$

Daya terpasan $\quad=40$

Jenis lampu = Floorescent;

jenis $\mathrm{x}^{-1}$

$\mathrm{FU} \quad=0,9$

$\mathrm{Fb} \quad=1$

$\mathrm{Q}=($ daya lampu, $\mathrm{w})(\mathrm{FU})(\mathrm{Fb})(\mathrm{CCF})$

$=(40)(0,9)(1)(0,82)$

$\mathrm{Q}=29,52 \mathrm{w}$

Panas total yang diberikan lampu pada beban perolehan panas

Qlampu $=29,52 \times 8=236,16 \mathrm{w}$

Aliran udara melalui pintu diabaikan karena akan terjadi jika ada perbedaan suhu yang besar antara dalam ruangan dan luar ruangan.

Tabel 6. perolehan kalor dari sumber pada jam 08.00;12.00;16.00

\begin{tabular}{|c|l|c|c|c|c|}
\hline Jam & Jendela & Dinding & Manusia & Lampu & Total \\
\hline 08.00 & 66,528 & 205,3025 & 5877 & 236,16 & 6384,990 \\
\hline 12.00 & 82,544 & 723,1362 & 2677,5 & 236,16 & 3719,340 \\
\hline 16.00 & 66,528 & 1906,784 & 2677,5 & 236,16 & 4886,972 \\
\hline \multicolumn{5}{|c|}{ TOTAL } & $14991,30 W$ \\
\hline
\end{tabular}

Dimana 1 PK diperhitungkan $9000 \mathrm{Btu} / \mathrm{h}$ Untuk pukul 08.00

Total panas $=6384,9905$ watt $\times 3,413$

$\mathrm{Btu} / \mathrm{h}$ $=21791,9725 \mathrm{Btu} / \mathrm{h}$

Untuk pukul 12.00

Total panas $=3719,3402$ watt $\times 3,413$

$$
\begin{aligned}
& \text { Btu/h } \\
& =12694,108 \mathrm{Btu} / \mathrm{h} \\
& =\frac{12694,108}{9000}=1,4 \mathrm{buah}
\end{aligned}
$$


Untuk pukul 16.00

Total panas

$$
\begin{gathered}
=4886,9729 \text { watt } \mathrm{x} \\
3,413 \mathrm{Btu} / \mathrm{h} \\
=16679,238 \mathrm{Btu} / \mathrm{h} \\
=\frac{16679,238}{9000}=1,85 \mathrm{buah}
\end{gathered}
$$

\section{PEMBAHASAN}

Dari hasil penelitian diatas diperoleh jumlah dipeoleh total jumlah kalor pada ruang kuliah prodi nautika.yang dapat dilihat pada tabel dibawah ini;

\begin{tabular}{|c|c|c|c|c|c|}
\hline Jam & Jendela & Dinding & Manusia & Lampu & Total \\
\hline 08.00 & 66,528 & 205,3025 & 5877 & 236,16 & 6384,9905 \\
\hline 12.00 & 82,544 & 723,1362 & 2677,5 & 236,16 & 3719,3402 \\
\hline 16.00 & 66,528 & 1906,7849 & 2677,5 & 236,16 & 4886,9729 \\
\hline \multicolumn{5}{|c|}{ TOTAL } & $14991,303 ~ W$ \\
\hline
\end{tabular}

Dalam perhitungan diambil tiga waktu karena waktu tersebut diatas merupakan waktu dimana taruna/I memiliki aktifitas yang sangat tinggi. Besarnya beban pendingin yang di hasilkan sangat mempengarui kerja dari mesin pendingin sehingga performansi dari mesin pendingin tidak maksimal. Besarnya beban pending akan dapat berpengaruh terhadap temperature dalam ruangan tetap tinggi sehingga tidak membuat nyaman dan juga memaksa kerja dari mesin pendingin tersebut serhingga dapat menagibatkan kerusakan pada komponen mesin pendingin tersebut. Dari hasil penelitian tiap kalor yang di hasilkan untuk tiap jam berbedabeda untuk perolehan kalor dari jendela terbesar diperoleh pada pukul 12:00 hal tersebut disebabkan oleh karena radiasi matahari pada jam 12:00 paling besar yaitu 67 sehingga perolehan kalor melalui jendela/kaca pada pokul 12:00 sebesar 82,544 watt. Perolehan kalor melalui dinding terbesar terjadi pada pukul 16:00 hal tersebut dikarenakan kondisi ruangan bagian selatan berhubungan langsung dengan lingkungan sehingga CLTD lebih besar dan luas daerah perpindahan panas yang kontak dengan lingkungan lebih besar sebesar 1906,7849 Watt.

\section{KESIMPULAN}

Dari hasi perhitungan diperoleh beban pendingin sebagai berikut:

\begin{tabular}{|c|c|c|c|c|c|}
\hline Jam & Jendela & Dinding & Manusia & Lampu & Total \\
\hline 08.00 & 66,528 & 205,3025 & 58,77 & 236,16 & 6384,9905 \\
& & & & & \\
\hline 12.00 & 82,544 & 723,1362 & 2677,5 & 236,16 & 3719,3402 \\
\hline 16.00 & 66,528 & 1906,7849 & 2677,5 & 236,16 & 4886,9729 \\
\hline \multicolumn{5}{|c|}{ TOTAL } & $14991,303 ~ W$ \\
\hline
\end{tabular}

\section{DAFTAR PUSTAKA}

1. Anwar, Khairil, dkk. Efek Temperatur Pipa Kapiler Terhadap Kinerja Mesin Pendingin. Jurnal Mekanikal, Vol.1 No.1 Januari 2010. Pp. 30-39.

2. Arismunandar, W., H.Saito. Penyegaran Udara. Edisi keenam, PT. Pradnya Paramita, Jakarta. 2002.

3. Gunawan Ricky,2000 Teknik Refrigerasidan Tata Udara

4. Hasan Basri, M. Pengaruh perubahan tekanan kondensor dan tekanan evaporator terhadap kinerja mesin refrigerasi focus 808. Thesis pascasarjana Universitas Hasanuddin 2007

5. Holman,J.P. 1994 . Perpindahan Kalor.Erlangga, Jakarta : Indonesia

6. Jordan, R.C. dan Priester, G.B., 1956, Refrigeration and Air Conditioning, Second

7. Edition, Englewood Cliffs, N.J.: Prentice Hall, Inc.

8. Stoecker, W.F. 1994 . Refrigerasi danPengkondisian Udara.Jakarta 